\title{
DEVELOPING CRITICAL IMPLEMENTATIONS OF TECHNOLOGY-RICH INNOVATIONS: A CROSS-CASE STUDY OF THE IMPLEMENTATION OF QUEST ATLANTIS*
}

\author{
MICHAEL K. THOMAS \\ University of Wisconsin-Madison \\ SASHA A. BARAB \\ Indiana University \\ HAKAN TUZUN \\ Hacettepe University
}

\begin{abstract}
This study examined the tensions surrounding the implementation of a technology-rich educational innovation called Quest Atlantis (QA) in a local public elementary school. Three qualitative case studies of three classrooms implementing the innovation and a subsequent cross-case analysis were undertaken to illuminate: 1) the reasons why teachers chose to implement the innovation in their classrooms; 2) the core challenges and tensions of implementing this innovation; 3 ) the supports necessary to successfully implement the innovation; and 4) the adaptation that the innovation underwent in the course of its implementation. The results of this study indicated that teachers implemented QA because of its alignment with their existing curricular goals, its flexible adaptivity, and its emphasis on social commitments. Findings also indicated that teachers persisted in using QA because the students
\end{abstract}

*This research was supported in part by a National Science Foundation CAREER Grant 9980081, and by a National Science Foundation Grant 0092831.

(c) 2009, Baywood Publishing Co., Inc.

doi: 10.2190/EC.41.2.a

http://baywood.com 
enjoyed it and were enthusiastic for its continued use. Core challenges and tensions in the implementation included security concerns related to QA's use of web-based communication features, providing appropriate technical and social support for implementation, and balancing the innovation's intended use and its actual use.

\section{INTRODUCTION TO THE PROBLEM}

Many educators have observed difficulties with implementing educational innovations in real world settings (Buechler, 1997; Fishman, Soloway, Krajcik, Marx, \& Blumenfeld, 2001; Fullan \& Pomfret, 1977). Researchers have pointed out that tensions often emerge when new innovative educational programs or approaches are actually implemented in real world settings. One of these tensions is between the intended manifestation of a particular innovation and the manifestation actually implemented. That is, observable gaps often develop between what the designers of an innovation envision for its implementation and what actually occurs when it is implemented (Barab \& Luehmann, 2003; Randi \& Corno, 1997; Squire, MaKinster, Barnett, Luehmann, \& Barab 2003).

This gap between intended curricula and actually implemented curricula has been the focus of many researchers and evaluators who take a fidelity approach to implementation research (Fullan \& Pomfret, 1977; Snyder, Bolin, \& Zumwalt, 1996). In this approach, the unintended variations or changes that appear during implementation in real-life contexts are looked upon as undesirable. They are seen as deviations from what the designers of the innovation intended and thus represent a threat to the fidelity of the innovation. The appearance of these variations has been termed the "mutation phenomena" (Berman \& McLaughlin, 1974, p. 10), and as mutations creep into an implementation, the innovation's integrity and ultimate effectiveness are called into question. Indeed, if an innovation deviates too much from what the designers originally intended, these mutations may be called "lethal mutations" that can threaten the survival of the innovation (Brown \& Campione, 1996). An innovation might also undergo "co-optation" in which it is taken over or co-opted by its hosts (Berman \& McLaughlin, 1975, p. 10). Both lethal mutations and co-optation represent threats to educational innovations, and different contexts may threaten the implementation process in varying ways.

Designers of educational innovations have tried to deal with the problem of local customization of designed innovations differently. Some have tried to strictly manage the amount of local customization an innovation takes on when implemented (Slavin \& Madden, 1996). However, this minimal flexibility, or fidelity approach to design and implementation has suffered from problems commonly associated with top-down reform initiatives. In the 1970s, the U.S. Department of Education commissioned a series of studies of broad scale educational innovations implemented throughout the United States. These studies 
conducted by the Rand corporation noted that a top-down approach to implementation is often fraught with problems (Berman \& McLaughlin, 1974, 1975, 1978; McLaughlin, 1990). These researchers concluded that such implementations tend to fail because they do not allow for local customization and are besieged by unpredictable local contextual factors. A one-size-fits-all "cookie cutter" approach to implementing educational innovations in multiple contexts is clearly one that has been problematic (Barab \& Luehmann, 2003). Reasons for this have been shown to include issues related to local cultures, histories, resources, support, and even the personalities of local stakeholders (Berman \& McLaughlin, 1974; Elmore, 1996).

This does not mean that externally designed and developed innovations can't be successfully implemented in local contexts. The manner and pace of the implementation clearly are important. Some researchers have noted that teachers can become interested in an innovation long after it has already been implemented by other teachers in the same school, once it has shown some success and they feel supported and confident enough to use it themselves (Crandall, 1983; Guskey, 1986; Huberman \& Miles, 1984). These teachers respond to the trialability of the innovation, that is the extent to which they can try it out or watch it being tried by early adopters (Rogers, 1995). Programs that are externally created may also find success if teachers are given the support, training, and the ability to have some ownership over the implementation of the innovation (Crandall, Loucks-Horsley, Baucher, Schmidt, Eiseman, Cox, et al., 1982; Huberman \& Miles, 1984; Miles \& Louis, 1990).

The Rand studies also suggested that mutual adaptation might better describe successful implementation of educational innovations (Berman \& McLaughlin, 1975; Fullan \& Pomfret, 1977; House, 1979). In this approach to designing and implementing innovations, local adaptation is not considered a threat to the program but is instead allowed for in its initial design. Innovators intentionally and purposefully design flexibility into their innovations to allow for adaptation to local contexts (Randi \& Corno, 1997). This approach is intended to thwart the difficulties commonly associated with cookie cutter designs and implementations. This flexible adaptivity or mutual adaptation approach allows an innovation to change in ways unanticipated by the designers so that it can be adapted to local contextual factors, thus aiding in multi-context implementation (Fullan \& Pomfret, 1977; Snyder et al., 1996; Squire et al., 2003).

However, flexible adaptivity in innovations comes with a price. If an innovation changes too much as it adapts to a given local context, it may cease to be the innovation as initially designed. How can an innovation mutate to adapt to new environments and circumstances without suffering lethal mutations? This tension between a designed innovation's balance between flexible adaptivity and maintenance of its innovative integrity is the focus of this study.

A newer approach to studying implementation has been termed curriculum enactment by Snyder et al. (1996). This approach moves away from the notions 
of fidelity and mutual adaptation by focusing on the experiences of teachers and students as they enact the innovative curriculum. The externally created innovation is viewed as a tool to be used by both teachers and by students in generating these experiences, and the teachers and students become designers of the curriculum and designers of the innovation (Snyder et al., 1996).

"Technology-rich" innovations present a number of problems when they are implemented in formal educational settings and are particularly in need of study (Cuban, 1986, 2001; Dede, 1998). Conducting design-based research (Brown, 1992; Collins, 1992) from a curriculum enactment perspective (Snyder et al., 1996) may offer both a method and a perspective that may help researchers fully understand and negotiate the challenges of implementing technology-rich innovations.

To better understand these tensions, this study examined the implementation of a technology-rich innovation called Quest Atlantis (QA). In this innovation, a 3D online virtual environment is used to frame educational activities called Quests that are nested to form unit plans. It functions in many ways like online video games such as "World of Warcraft" making use of a virtual world to situate activity. The required use of computers to access and participate within the virtual world makes QA a technology-rich innovation. In this study, the researchers served as both designers and implementers of a technology-rich educational innovation (QA) in a local elementary school. This perspective allowed the researchers to observe and document QA's design, implementation, and redesign in a naturalistic context, and enabled the researchers to construct an account illuminating the struggles this innovation experienced as it was implemented in three different classrooms in a local elementary school. The fact that the researchers were also designers who sought to build theory makes this an example of design-based research.

This study takes a curriculum enactment approach to researching the implementation of QA in three separate classrooms in a single school, focusing on teachers and students and their impact. The period of study was one spring semester of one school year or approximately 4 months. During this period, the researchers made regular visits to the site, interviewed teachers, students, and other school and QA staff members, and took field notes while also working to support the implementation. Using qualitative methods to build three case studies and a cross-case analysis, a design-based research perspective was taken to build understanding of the implementation of QA with a view toward building theory on the implementation of technology-rich innovations in public school settings.

\section{QUEST ATLANTIS AS A FLEXIBLY ADAPTIVE DESIGN}

QA, the innovation implemented in this local elementary school and the subject of this study, was inspired by the work of Michael Cole and the Fifth Dimension project (Cole, 1996). QA is an innovative technology-rich program that seeks to 
inspire and educate children ages 9 to 12 in ways that are fun and entertaining, and makes use of what McLellan (1996, p. 459) calls "through the window" virtual reality. A computer-generated online 3D world accessible to multiple users in real time situates QA activity. Such multi-user environments are common for online games and social spaces, and are known as multi-user virtual environments or MUVEs.

The QA interface uses a two window web browser system that allows users to view the 3D virtual environment using one browser window while simultaneously viewing $2 \mathrm{D}$ web pages in another window. The $3 \mathrm{D}$ view allows for both first person viewing, in which the environment is viewed from the eyes of the user, or third person viewing, in which users view themselves as part of the 3D space as avatars-virtual place holders that represent individual users. Users may interact with one another using both avatars and a real-time chat function. Users may also interact with the 3D environment itself, exploring the virtual worlds and the objects and structures within them. QA contains several different virtual worlds. Ocean World is one example and it is an underwater environment that contains Quests about the oceans. Users may trigger events in the 3D space by touching or clicking on certain objects or by proximity. One event that may be triggered in this manner is "teleporting" or transporting from one QA virtual world to another.

When in the virtual 3D environment, Questers can "walk around" and find spinning disks that, when clicked, launch Quests. These Quests can be assigned by teachers or the students can find them for themselves. The Quests can also be accessed by way of a "gateway" that allows them to engage Quests without using the 3D space. Each Quest contains a description of the Quest "mission," a list of goals or tasks to be completed by the quester, and some resources that help the Quester complete the tasks. Questers may type responses to Quests or they may upload up to four file attachments (e.g., word documents, excel spreadsheets, PowerPoint presentations, or even recorded videos) to respond to the Quest.

Hundreds of Quests have been developed for QA covering a variety of content areas, and each Quest is connected to MCREL (Mid-continent Research for Education and Learning) national academic standards. When Questers respond to Quests, their responses are uploaded into the QA system and then accessed by a teacher or other designated educator who reviews the Quest and gives feedback. Next, the Questers access their work and the feedback by way of their 2D home page. In this way, the Questers' QA homepages serve as online portfolios of their work with the accompanying feedback from teachers. In addition to the computer-based aspects of QA, the QA team of designers also developed other materials to support the project. These included items such as QA trading cards, t-shirts, pencils, comic books, a QA novel, a QA board game, and other items.

QA was designed to be a technology-rich innovation that would not only support students' growth by way of content learning but also support the development of students' character. To this end, the innovation explicitly advances seven 
"social commitments." These social commitments are intended by the designers to permeate the action that takes place in QA, and just as all of the Quests in QA are matched to educational standards, they are also matched to one or more of the social commitments. By doing so, QA seeks to foster an awareness of these concepts among the children (and adults) who use the innovation. The seven social commitments are articulated as brief phrases followed by slogans that are intended to further elucidate them (see Figure 1).

The social commitments were developed by QA designers in conjunction with stakeholders at the local Boys and Girls Club that served as the alpha site for the innovation. These social commitments were considered to be an essential part of QA, and extracting these commitments would render moot the essential reason for questing in the first place, which is to improve the condition of the world. While it may happen that certain localities choose to stress certain commitments or make minor modifications in order to suit their particular context, abandoning them entirely would constitute a lethal mutation in the view of the QA design team.

\section{Research Questions}

This study examined the implementation of QA as a technology-rich educational initiative in three separate contexts, with the unit of analysis being the teacher implementing the program. Three case studies of these three contexts were used to understand how QA was implemented and enacted in these contexts, and a cross-case analysis of the three teachers was also conducted. The following questions were specifically addressed:

1. Why do teachers choose to implement Quest Atlantis?

2. What are the core challenges and tensions of implementing Quest Atlantis in each classroom and what are the cross-classroom themes?

\begin{tabular}{|l|l|}
\hline Social Commitment & Slogan \\
\hline Creative Expression & "I Express Myself” \\
Diversity Affirmation & "Everyone Matters" \\
Personal Agency & "I Have Voice” \\
Social Responsibility & "We Can Make a Difference" \\
Environmental Awareness & "Think Globally, Act Locally" \\
Healthy Communities & "Live, Love, Grow" \\
Compassionate Wisdom & "Be Kind" \\
\hline
\end{tabular}

Figure 1. QA's social commitments. 
3. What supports are necessary to successfully implement Quest Atlantis in multiple classrooms?

4. In what ways does Quest Atlantis adapt to local context(s) of implementation?

\section{METHODOLOGY}

\section{Design-Based Research}

The focus of this study is the implementation of an innovation in naturalistic, as opposed to laboratory, settings. In addition to being researchers interested in studying implementation, learning scientists are also frequently designers who are involved in changing the very contexts they are researching (Barab \& Squire, 2004). Researchers attempting to build vivid accounts of real-world participation in designed contexts must wear two hats, that of the researcher and that of the designer. It might also be said that a third hat, that of an implementer, is also appropriate for one who designs an intervention and researches its implementation. Such a designer-researcher conducts what has been termed a design experiment (Brown, 1992; Collins, 1992). Design experiments allow researchers to investigate the design and the implementation of innovations at the same time, while developing theories in complex and dynamic environments or learning ecologies (Cobb, Confrey, diSessa, Lehrer, \& Schauble, 2003; Collins, Joseph, \& Bielaczyc, 2002). As the design and development of the innovation unfolds over time, the designer-researcher may use both qualitative ethnographic and quantitative approaches in order to conduct formative evaluations of the innovation, informing its design while building learning theories to inform further design and development (Fishman, Marx, Blumenfeld, Krajcik, \& Soloway, 2004).

In the present study, the researchers played multiple roles with respect to the QA project. The researchers worked for the QA project, doing design, development, organizational and implementation work in addition to playing the role of researcher. This unique perspective allowed the researchers to observe and document the innovation's design, implementation, and redesign in the real-life context of a local elementary school.

\section{Case Study}

Yin (1981) defines a case study as an empirical inquiry with a trifecta of elements: (a) the investigation is of a contemporary phenomenon within its real-life context; (b) the boundaries between the phenomenon and context are not clearly evident; and (c) multiple sources of evidence are used (Crosthwaite, MacLeod, \& Malcolm, 1997).

In this approach, naturalistic interpretations are created based on qualitative data (Guba \& Lincoln, 1983; Stake, 1983, 1995; Yin, 1981, 1989). A case is a "bounded system" that draws attention to itself "as an object rather than a process" 
(Stake, 1995). This approach was used to examine the three cases of three teachers using QA in their respective classrooms and with their respective students, and is appropriate as it allows for the use of mixed methods for the exploration of a bounded system (in this case, a classroom) over time in a way that is rich in context (Creswell, 1994, 1998; Merriam, 1988; Stake, 1995). All three teachers work in the same public elementary school and began using QA at the same time. Although all three teachers are in the same school, the manner in which QA was used in these three contexts differed considerably. This variability will speak to the implementation literature on flexible adaptivity and enactment and will have implications for implementing, sustaining, and scaling up QA and similar educational innovations.

The constant-comparison method (Glaser \& Strauss, 1967; Strauss \& Corbin, 1998) supported the generation of a list of core issues that are presented here as assertions and guide the development of case descriptions for each classroom. Each case is presented separately with an eye toward highlighting themes identified through the constant-comparison methods. After investigating the individual cases, a cross-case comparison study using Stake's (1983) case study methodology was conducted.

Cross-case analysis was determined to be an appropriate and illuminating examination method as it allowed for comparisons between cases so that themes or generalities related to the research questions may be discerned. More specifically, the cases were analyzed using composite sequence analysis and case level meta-matrices (Miles \& Huberman, 1994) so as to construct a typical story that describes the implementation of QA in these separate contexts. The researchers based much of this comparison around the core themes identified during the constant-comparison analysis, with additional themes identified in the development of integrated cases. In this way, it became possible to compare data from the three cases and observe any emergent themes, patterns or commonalities.

\section{Context of this Study}

The study took place at an accredited mid-western elementary school located in a mid-size city - defined as a central city of a Consolidated Metropolitan Statistical Area (CMSA) with a population less than 250,000. Of the nearly 500 students enrolled during the research period in this grade 3 to grade 6 school, $83 \%$ are White, $4 \%$ Black, $2 \%$ Hispanic, and $4 \%$ Interracial. As a marker of socio-economic status, $14 \%$ of the students received free lunch and $3 \%$ received a reduction in lunch price. The school had a well-equipped computer lab, and each teacher also had two older machines in his/her classroom with Internet connections. All the classroom and lab computers had the QA software installed. The three teachers were female, selected for the case studies because they were the first three teachers who agreed to implement QA and were willing to participate in the study. 


\section{Data Collection}

The three case studies were created using various data collections methods associated with qualitative research and case study methodology. The following sources of data were used, resulting in approximately 250 single-spaced pages of text for analysis:

Interviews

Interviews were conducted with five students in each of the three classes investigated. Each of the three teachers were interviewed twice, once during the implementation and once after the school year finished. One of the teachers went on maternity leave during the latter period of data collection at the school and was replaced by a substitute. The computer lab assistant who worked with the QA design team as well as with the school was interviewed. The principal of the school was interviewed. A member of the QA design team who consistently worked with one of the teachers was interviewed twice. All interviews were transcribed and subsequently coded using the QSR N-Vivo software for qualitative research.

\section{Online Portfolios}

The collective work of all of the students in the three classes were captured electronically by the QA interface and informed the case studies. This includes all of the Quest responses (430) the students completed or attempted in the period of data collection as well as feedback from Quest reviewers who were teachers and QA staff members.

\section{Activity Logs}

The following records of activity of the teachers and the students were captured by the QA interface and used to characterize the QA activity in each classroom: chat logs (everything stated in the QA 3D space was captured during the period of data collection), the number of login times, the number of chat lines uttered by every user, the number and content of e-mails received and sent using the QA system, the number of accepted Quests, the number of pending Quests, the number of Quests to revise, the number of saved Quests, and the number of total Quests attempted.

\section{Field Notes}

The QA researchers and designers wrote field notes throughout the research project, and these were collected and analyzed as part of the case studies. These notes include logistic information, a general overviews of the "goings on" at QA sites, narrative descriptions, and analytical reflections (Erlandson, Harris, Skipper, \& Allen, 1993). Participant observation in this study involved observing 
participants in situ and focused on the evolving technical structures as well as the social relationships, interactions, and conversations that take place at these sites. As a designer, developer, and implementer of QA, the researchers were in a position to record occurrences that were both observed and participated in. The field notes were also coded using QSR N-Vivo.

\section{Document Analysis}

A considerable number of documents collected from the site were analyzed and informed the case studies. They included documents provided by the school, handouts prepared by teachers for the use of QA in their classrooms, QA Manuals, QA meeting notes taken by QA staff members, and e-mail correspondence between QA staff members during the research period. Also, Questers' home pages are designed to compile their work through the QA experience, so that their work over time may be archived and viewed in the context of the program. Analyses of these online portfolios, including their reflections, were also used to build an understanding of QA implementation stories.

\section{Data Analysis}

As is the case with any research approach, assertions in a qualitative study must be grounded in data sources. By grounding assertions, illustrative stories recounted in the study can be said to be representative of other similar stories. In this way, any underlying patterns that emerge through the process of data analysis can be considered representative of observable phenomena.

Multiple sources of data (interview transcripts, field notes, documents, e-mail correspondence, print outs of students' work, chat logs, and meeting notes) allow for triangulation of findings. Member checks were also conducted with the three teachers during the study, triangulating and increasing the validity of the findings (Guba \& Lincoln, 1983; Merriam, 1988). Additionally, peer examination took place in which colleagues were asked to comment on emergent findings (Merriam, 1988). These peers included the QA Principal Investigator (PI) and design team members, as well as other colleagues with research experience and/or familiarity with QA and the context in question.

To identify emergent issues to become the focus of more robust analysis, a constant-comparison approach was taken. The constant-comparison method allows for the systematic analysis of data gathered by way of qualitative means (Glaser \& Strauss, 1967; Strauss \& Corbin, 1998). The systematic means called for by this approach involves coding, which with qualitative data entails assigning meaning to units of text (written and spoken), which are used to build grounded (supported) assertions. Constant-comparative coding involves coding textual data and building categories of codes by constantly coding and comparing these codes with one another (Glaser, 1992). In this way, categories and their properties are discovered by the analyst. Once the categories are created and connections are 
forged within these categories, selective coding is then performed to discover the relationships between categories and the core categories in order to integrate and refine emerging assertions (Barab, Thomas, \& Merrill, 2001; Strauss \& Corbin, 1998).

This cross-case study used qualitative research and constant-comparison methods to build assertions and theory about implementing technology-rich innovations in authentic contexts. An interpretivist ontological perspective was taken by the researchers and, keeping with a grounded approach to data analysis, the constant comparison method with coding and memoing was utilized. The study looked at implementation from an enactment perspective, focusing on teachers and students who made use of the QA innovation. Assertions presented in the following section are grounded in the data, and further validated by the use of multiple data collectors, multiple coders, and member checks.

\section{RESULTS}

\section{Categories of Analysis}

The analysis of the data involved coding the transcripts of 20 interviews. Using the constant comparison method, we coded the interviews line-by-line until we reached $100 \%$ inter-coder agreement on how bits of text should be coded. The researchers deliberated, discussed, and debated the codes throughout this process. This added to the reliability of the coding and served as a means for triangulation. In this way, at least two coders monitored one another during the entire coding process so as to check one another's understanding of the text, the codes that annotated the text, and the collapsing of the codes into categories. The coding and categorization of codes was accomplished with the use of the qualitative research software package QSR N-Vivo.

A total of 494,079 characters and 4,956 paragraphs were coded. The coding resulted in 320 unique codes. By continually comparing and reexamining the codes, the associated data, and our understanding of previous research, these 320 codes were eventually assembled into 16 categories as two researchers worked toward the goal of achieving parsimony while at the same time capturing as much of the entire data as possible. These categories contain data that is not mutually exclusive, in that codes grouped under one category might also be placed under another one as well.

Counting the coded characters and paragraphs with the QSR N-Vivo software allowed the researchers to get a sense of how much of the textual data buttressed the codes. Then, MS Excel was used to create tables of percentages of individual codes, which allowed for the ranking of codes with respect to both character percentage and paragraph percentage. To account for the difference between character percentages and paragraph percentages, the two numbers were averaged to find what is presented here as the "character paragraph mean weight." 
For example, one code - "teaching philosophy"-was used for examples in the data in which teachers mentioned or discussed their teaching philosophy. There were 19 separate passages coded in this way. These passages came from 6 different documents containing 10,278 characters in 38 paragraphs. The code "teaching philosophy" was one of 71 codes collapsed into the category "Implementation" (see Figure 2).

Although the coding and the collapsing of the codes yielded some useful generalizations, the categories were hard to collapse because of overlap between the different codes. Some examples of this are the codes "3D" and "3D structures," or "teacher" and "other teacher." Another problem was that the resulting categories did not lend themselves easily to matching with the research questions. Some categories simply contained too much data to be useful (the "Implementation" category contained over 450 separate passages) while others contained too little data to be useful (the "QA extras" category contained only 13 passages). Further, it became apparent that some of the categories did not capture some of the richness of the data.

This prompted the researchers to look back at the research questions and align the codes based on the research questions one at a time. This ultimately involved a five stage process. First, the researchers went through all of the categories and reread all of the passages in all of the codes for the 16 categories. Second, passages that spoke directly to each research question were pasted into a new document with notations on how the passages were originally coded. This was done for all three cases, for all four research questions. Third, a list of "answers" or "responses" to the research questions was drawn up for each of the three cases for all four research questions. Fourth, individual codes were then matched with the answers to the research questions. Fifth, the list of answers to the research questions were refined so as to accord with the new alignment of answers to the research questions (theories) and the coded data. In this way, the answers to the research questions have grounded support in the coded data.

Both categories and individual codes were used to illuminate the four research questions. While the original distinction between category and code became less meaningful as the study progressed, the original distinction allowed the researchers to become intimately familiar with the data and with the relationships between elements in the data. Furthermore, the categories help to explain the "weightiness" of different elements in the data.

\begin{tabular}{|l|c|c|c|c|c|c|c|}
\hline $\begin{array}{l}\text { Node } \\
\text { (Imple- } \\
\text { mentation) } \\
\text { teaching } \\
\text { philosophy }\end{array}$ & $\begin{array}{c}\text { Passages } \\
\text { Coded }\end{array}$ & Characters & Paragraphs & Documents & $\begin{array}{c}\text { Character } \\
\text { Percentage }\end{array}$ & $\begin{array}{c}\text { Paragraph } \\
\text { Percentage }\end{array}$ & Average \\
\hline
\end{tabular}

Figure 2. 


\section{The Three Cases}

The information presented in the introductions to the three classes was gleaned from the interviews, field notes, QA staff meeting notes and correspondence, school-provided documents, and the QA database that tracks e-mail, chat, and Questing activity. After a brief description of the nature of each participating classroom, comparisons will be drawn between the three cases so as to develop grand assertions that respond to the research questions.

\section{Laura's Class}

Laura has been teaching for 12 years, and during this research period she taught a 4th grade homeroom class and had 27 students. Laura used to teach preschool for special needs children, and had several inclusion children in her classroom and one ELL (English Language Learner) student. She is interested in oceanography in particular, science more generally, and the history local to her town. She has a Master's Degree in Education and formerly was a science teacher but is now a homeroom teacher. She is a parent of a child with special needs.

Laura was happy to have QA staff members and assistants review the quests her students accomplished and, indeed, QA staff did the majority of her reviews. She has also never used the QA rubric for reviewing quests and considered the task of reviewing quests "overwhelming." During the research period, Laura assigned her students six different quests, all of which have a science focus, and the non-assigned quests that were completed were done by the students in their own time. Although she expressed some fear about using technology, Laura has embraced the program wholeheartedly. Laura did her student teaching years ago with Jane, one of the QA staff members, and Jane took it upon herself to work closely with Laura as she implemented QA.

\section{Beatty's Class}

Beatty has been teaching at Patrick Henry Elementary School for 5 years, and her 4th grade class has 29 students. Her class has six inclusion students, a number of ELL students, and one student who had been home-schooled until the time of this study. She said that nearly half of her students are labeled in one way or another. Prior to becoming a teacher, Beatty was in sales and support for nearly 20 years, and had also been a computer programmer. Beatty was introduced to QA by Wanda, the first teacher in the school who had adapted Quest Atlantis, and Beatty said that she was immediately interested in QA both because it was an innovative project using technology and because she was formerly a computer programmer.

Beatty is known among colleagues at her school for being a left-wing political activist. She regularly has a folk singer come into her classroom to work with the students on writing protest songs. She is also fascinated by Native Americans, and 
this year, she and her students did a play they wrote that is based on Shakespeare's "Romeo and Juliet" but with the two main families being replaced by white settlers and American Indians. She had been warned about being too actively against the war in Iraq and, although the superintendent of the district issued a memo about not protesting the war, Beatty had already staged a public protest against the war with her class.

One of her first QA activities was to have all of her students fill in their QA home pages. She began QA as soon as she could, jumping ahead of an 'introduction to QA' meeting conducted by our team to four other teachers. She started by sending small groups of students to the computer room to use QA in early December. Once she got a few students to do it, she had them teach other students in small groups and had them show less experienced students how to fill in their QA home pages. This is a model that she also used with later collaborations with QA users in Australia. She began by having a few students over winter break e-mail some Australian students. Now the students are sharing information about one another as well as photographs and are using them to create Power Point presentations about one another.

Beatty likes to control everything going on in the classroom. She is spontaneous and enjoys having visitors and helpers in the classroom. She likes to teach on the floor while working independently with groups of students and can be very strict at times with the students. Beatty does all of her quest reviews herself. She has never used the QA quest rubric. Although the QA design team developed pre- and post-tests for units Beatty has used in her classroom as QA activities, she insisted on not using them and instead developed her own assessments.

For Beatty, QA is a vehicle for talking about social commitments. What is interesting to Beatty is not the content but rather the "attitude" of QA. About this she says: "I'm not a content person. I'm looking for the experience of how (it's) going to affect kids socially. It could become (just) another lesson if we don't keep that in mind." She is interested in the activism of QA and building connections between the problems that exist in the mythical Atlantis created by the QA design team and local struggles in area surrounding the school. In fact, she considers the legend of QA to be one of its strongest components.

\section{Wanda's Class}

Wanda had been teaching for 8 years, 6 of which have been at Patrick Henry Elementary School, and had 31 students in her 5th grade classroom. She has a Master's Degree in Elementary Education and, while a student of the QA PI, studied the use of computers in education. QA implementation began in this school when the PI and another QA staff member contacted her. After an initial meeting, a presentation was arranged at the school which led to more interest and eventually the implementation of the innovation. In this, the first year of QA at Patrick Henry, Wanda became pregnant and had maternity leave approximately 3 months before the end of the school year. 
Wanda was very enthusiastic about using technology to teach. There were three LEP students in her classroom, one of which spoke no English at all during the research period, and there were also four special needs children. Her classroom atmosphere was generally good-spirited, and a general feeling of positive energy permeated the classroom. When Wanda implemented QA, she was very clear that the students should not use QA for "socializing," and noted especially that the QA e-mail and chat should only be used for "questing." However, she was supportive of her students who used QA for collaborating with Questers from Denmark and Australia.

Wanda began using QA in her class with an "Agents of Change" unit plan about people who have changed the world, which began right around Martin Luther King Day. Her class was the most active group of Questers at Patrick Henry during the research period, completing over 100 Quests, renting many plots of land in the virtual environment, and signing up for the jobs of chat monitor, help desk, tour guide, greeter, etc. inside the online 3D space. The students did roughly the same quests as Beatty's class; however, their work was more extensive in that the students provided more substantive responses to the quests. Mindy, a student teacher, also helped in Wanda's class by assisting students with completing quests as well as introducing QA activities.

In the latter portion of the research period, a full-time substitute (Rachel) took Wanda's place in her classroom while Wanda was on maternity leave. For the sake of simplicity, the class will be referred to as Wanda's class throughout.

\section{CASE COMPARISONS}

In researching the implementation of QA with the teachers and classrooms as described above, certain themes emerged that can be used to characterize the implementation of QA across their respective classrooms. These issues are derived from an analysis of the data collected during the research period and are compared with data gleaned from the QA database. Descriptive comparisons of the three classes are explored, and then a three-case comparison to the four research questions is presented.

\section{Descriptive Comparisons}

To paint a picture of the QA activity in the three classes, Figure 3 includes usage data on the students as a whole and the individual teachers, including log on times and the numbers of chat lines, e-mails, and accepted quests. This data may be considered QA engagement data in that higher numbers indicate greater engagement with QA. Wanda's class, for example, did much more chatting in the QA 3D space than either of the other two classes indicating greater engagement with QA: 


\begin{tabular}{|l|c|c|c|c|c|}
\hline & $\begin{array}{c}\text { Class Log } \\
\text { On Times }\end{array}$ & $\begin{array}{c}\text { Individual } \\
\text { Teacher Log } \\
\text { On Times }\end{array}$ & $\begin{array}{c}\text { Class Lines } \\
\text { of Chat }\end{array}$ & $\begin{array}{c}\text { Number of } \\
\text { E-mails } \\
\text { by Class }\end{array}$ & $\begin{array}{c}\text { Number of } \\
\text { Accepted } \\
\text { Quests }\end{array}$ \\
\hline Laura & 1,050 & 39 & 2,864 & 29 & 79 \\
Beatty & 1,436 & 93 & 2,290 & 228 & 87 \\
Wanda & 3,647 & 30 & 35,272 & 474 & 164 \\
\hline
\end{tabular}

Figure 3. QA usage by aggregated students and individual teachers.

As shown in Figure 3, Wanda's class logged on to QA far more often than Laura or Beatty's classes, and this reflects both their work and their social interactions in the online 3D space. Interestingly, though, is that when we look at the number of $\log$ on times for the teachers, Wanda logged on less frequently that either Beatty or Laura. Additionally, and not reflected in Figure 3, Wanda's substitute teacher Rachel did not log on to QA at all during the research period. Instead, Eydi and Mindy managed QA functions in Wanda's busy class. The figure also reflects the ownership that Beatty took with the implementation of QA in her class and her insistence that she be the manager of her quest reviews.

Looking at the lines of chat produced by the students and teachers in the different classes we see an even starker picture of the disparity in QA activity. Wanda's class produced more than 12 times the number of chat lines as Laura's, the next most active class. In Wanda's class, six Questers produced more than 2,000 lines of chat each, one of which was responsible for over 8,000 lines. The total number of lines of chat for these six was 27,379 or $78 \%$ of the total 35,272 lines produced by the entire class. As these six students were only $18 \%$ of the Questers in Wanda's class, this indicates that the implementation of QA in this context was accompanied by the emergence of an enthusiastic group of students that can be looked upon as a local cultural phenomenon.

A similar story can be seen regarding the use of QA e-mail in the three classes. Wanda's class far and away produced more e-mail messages than the other two classes. A significant amount of "spam" was produced by the Questers in Wanda's class, as they managed to send messages to all the Questers in QA, not just their schoolmates. The QA designers later disabled this function, restricting a Quester's ability to e-mail large groups of other Questers.

The number of accepted quests probably best represents QA activity related to learning. An "accepted" quest is one that was attempted by a Quester, then reviewed by a teacher or other QA reviewer and accepted as complete, as opposed to quest responses that need to be revised. Thus, only quests that were entirely completed to the satisfaction of the reviewers were considered to be an indicator of 
QA activity. Thus, it is notable that Wanda's class had twice the number of quests accepted in the next most active class by this indicator, Beatty's class.

\section{RESPONSE TO RESEARCH QUESTIONS}

The research questions were primarily illuminated by the codes and categories from the coding of the interview data listed in the tables provided below for each research question. The word "primarily" is used here because relevant information did come from other categories and codes but to a lesser extent. Furthermore, some passages were assigned more than one code. Quotes that directly spoke to the research questions are offered from each case for all four research questions so as to provide examples of how the research questions were illuminated by the data.

\section{Research Question 1}

Laura, Beatty, and Wanda all individually chose to implement QA because they each felt that it fit with what they were already doing in terms of content. In addition to the subject matter, all three teachers also used QA as a vehicle for writing and for engaging their students in higher level thinking. Beyond these commonalities, each teacher had other specific reasons for choosing to implement QA. Laura was pleased that curricular standards were met, and she also felt that QA worked well with both special needs and LEP students. She also liked that QA staff members were very responsive to her needs and requests.

Beatty, on the other hand, used QA as a way to empower students and to give them a voice or sense of agency. Interestingly, she also believed that the QA social commitments matched her own, and that QA was a good vehicle to support these commitments. Wanda, like Laura, noted the fit with curricular standards and that she felt it worked well with special needs and LEP students. Additionally, she liked that QA provided "one stop shopping," or a means for providing multiple avenues for engaging students in a single place. Wanda also believed that it was useful to motivate children using technology and media, and that her students liked QA and its customizability (see Table 1).

\section{Research Question 2}

The core challenges in implementing QA in Laura's class were: a) the need for staff support for reviewing quests; $b$ ) inappropriate behavior while chatting; c) dispensing QA trading cards; d) a lack of pre-questing activities to situate QA activity in the classroom; and e) the fact that QA staff presented all of Quests in Laura's classroom.

The core challenges in implementing QA in Beatty's class included Beatty's "fierce" independence and autonomy, and the fact that she created and conducted all pre-questing activity by herself. In one respect, this was not a problem. Beatty's 
Table 1. Summary of Research Question Findings for Each Case

\begin{tabular}{llccc}
\hline Question & Answer to Research Question & Laura & Beatty & Wanda \\
\hline Research & It fits with what we're already doing & $\checkmark$ & $\checkmark$ & $\checkmark$ \\
Question 1: & As a vehicle for writing & $\checkmark$ & $\checkmark$ & $\checkmark$ \\
Why do & Higher level thinking & $\checkmark$ & $\checkmark$ & $\checkmark$ \\
teachers & Special needs students & $\checkmark$ & & $\checkmark$ \\
choose to & LEP students & $\checkmark$ & & $\checkmark$ \\
implement & Content learning related to standards & $\checkmark$ & & $\checkmark$ \\
Quest & & $\checkmark$ & $\checkmark$ \\
Atlantis? & Empowerment & & & \\
& QA designers are responsive to our needs & $\checkmark$ & & \\
& Social commitments & & $\checkmark$ & \\
\hline
\end{tabular}

independence was indicative of her enthusiasm for the project and allowed her to adapt QA to her own needs and wishes. At the same time, she was somewhat of a maverick in the school and this may have created some distance between her implementation of QA and other teachers who were watching to see how early adopters were taking to this innovation. If early adopters are viewed as more mainstream teachers, the innovation may benefit from its early trials. This is in line with Roger's (1995) notion of an innovation's trialability.

The core challenges in implementing QA in Wanda's class were (like in Laura's class): a) the need for staff support for reviewing quests; b) problems with chat; c) dispensing QA trading cards; d) developing pre-quest activities independently like Beatty, as well as developing quest packets; and c) a QA e-mail spam problem. Finally, building in the 3D space among Wanda's students was a challenge, as was students using QA quests as writing workshops, QA lab time becoming typing time for some students, and the transition to Rachel, the long-term substitute teacher. For Rachel, science lesson time tended to "become" a QA activity time (see Table 2).

\section{Research Question 3}

The primary support necessary for Laura's class to implement QA was a full time staff supporter. Such support involved not only technological concerns, but also alleviating the concerns of teachers, parents, and staff regarding the QA online chat function and e-mail. The deep level of support may have limited feelings of implementation ownership with Laura, and she offloaded many administrative tasks to her QA support staff member. 
Table 2. Summary of Research Question Findings for Each Case

\begin{tabular}{|c|c|c|c|c|}
\hline Question & Answer to Research Question & Laura & Beatty & Wanda \\
\hline $\begin{array}{l}\text { Research } \\
\text { Question 2: }\end{array}$ & $\begin{array}{l}\text { Reviewing quests required } \\
\text { support, particularly from Eydi }\end{array}$ & $\checkmark$ & & $\sqrt{ }$ \\
\hline \multirow{7}{*}{$\begin{array}{l}\text { What are the } \\
\text { core challenges } \\
\text { and tensions of } \\
\text { implementing } \\
\text { Quest Atlantis } \\
\text { in each classroom } \\
\text { and what are the } \\
\text { cross-classroom } \\
\text { themes? }\end{array}$} & Chat problems & $\checkmark$ & \multirow{5}{*}{$\checkmark$} & $\checkmark$ \\
\hline & Dispensing trading cards & 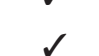 & & $\checkmark$ \\
\hline & Pre-questing activity & & & $\checkmark$ \\
\hline & A lack of pre-questing activity & $\checkmark$ & & \\
\hline & Eydi presenting all Quests & $\checkmark$ & & \\
\hline & Fierce independence & & $\checkmark$ & \\
\hline & $\begin{array}{l}\text { Science lesson "becoming" a } \\
\text { QA activity }\end{array}$ & & Rachel & \\
\hline
\end{tabular}

The supports necessary for Beatty's class to implement QA were pre-questing activities that she created for her own class. However QA required only a little technical support as Beatty's technology-related experience as a former computer programmer allowed her to be very autonomous in her practice. With Beatty, we found that a maverick or "against the grain" teacher may need support in effectively communicating with more "mainstream" teachers. This kind of support was not technical but involved QA staff listening to Beatty's stories and concerns on an almost daily basis. This was a more personal kind of support that is not often accounted for in implementation literature.

Like with Laura's class, we found that the supports necessary for Wanda's class to implement QA included a full time QA staff supporter. Again, support involved alleviating concerns of teachers, parents, and staff regarding the QA online chat function and e-mail. Wanda's students also needed a lot of support for QA to be implemented, and such support included the process for dispensing extrinsic rewards for completing quests. Similarly to Beatty's class, pre-questing activities were important. Finally, making use of the writing process (an iterative approach to writing in which students are encouraged to complete multiple drafts before completing a writing work) and QA staff support for 3D building in the QA virtual environment was required.

In addition to findings regarding support from the three cases, we also found that: a) obtaining and maintaining the support of the school principal was important: b) Questers supported one another and even supported teachers in the QA online 3D space; and c) QA staff members helped questers in QA online 3D space (see Table 3). 
Table 3. Summary of Research Question Findings for Each Case

\begin{tabular}{|c|c|c|c|c|}
\hline Question & Answer to Research Question & Laura & Beatty & Wanda \\
\hline $\begin{array}{l}\text { Research } \\
\text { Question 3: }\end{array}$ & $\begin{array}{l}\text { Support of a full-time QA supporter } \\
\text { (Eydi) was important }\end{array}$ & $\checkmark$ & & $\checkmark$ \\
\hline What sup- & QA required a lot of support & $\checkmark$ & & $\checkmark$ \\
\hline $\begin{array}{l}\text { necessary } \\
\text { to success- } \\
\text { fully imple- } \\
\text { ment Quest }\end{array}$ & $\begin{array}{l}\text { Support involved alleviating concerns of } \\
\text { teachers, parents, and staff regarding } \\
\text { the QA online chat function and e-mail }\end{array}$ & $\checkmark$ & & $\checkmark$ \\
\hline \multirow{5}{*}{$\begin{array}{l}\text { Atlantis in } \\
\text { multiple } \\
\text { classrooms? }\end{array}$} & $\begin{array}{l}\text { Rewards and the process for dispensing } \\
\text { them was part of supporting } Q A\end{array}$ & $\checkmark$ & & $\checkmark$ \\
\hline & $\begin{array}{l}\text { Pre-questing activities were important in } \\
\text { supporting QA }\end{array}$ & & $\checkmark$ & $\checkmark$ \\
\hline & $\begin{array}{l}\text { Support may have limited a feeling of } \\
\text { ownership }\end{array}$ & $\checkmark$ & & \\
\hline & $\begin{array}{l}\text { A maverick or "against the grain" teacher } \\
\text { may need support in effectively com- } \\
\text { municating with more "mainstream" } \\
\text { teachers }\end{array}$ & & $\checkmark$ & \\
\hline & $\begin{array}{l}\text { Supporting for the writing process was } \\
\text { part of supporting } Q A\end{array}$ & & & $\checkmark$ \\
\hline
\end{tabular}

\section{Research Question 4}

QA adapted to local contexts in Laura's class in that I-BURST rules became a permanent part of QA. This was a set of guidelines intended to encourage children to act appropriately and responsibly while interacting with others in QA. I-BURST stands for: Include everyone, Be careful sharing, Use good words, Respect others, Support all, and Talk to someone new. Ocean World and Healthy World also became a permanent part of QA in response to what happened in Laura's class. QA adapted to local contexts in Beatty's class in that the myth underpinning QA was deepened and Quests were done internationally (Beatty's students co-quested with students from Australia). QA adapted to local contexts in Wanda's class in that I-BURST rules became a permanent part of QA, the myth underpinning QA was deepened, the optional quest response rubric became 
a permanent part of QA, QA jobs and 3D online community were further developed and the QA board game was used in her class (see Table 4).

\section{IMPLICATIONS}

The research questions focused on four areas: a) teachers' motivations for implementing QA (Q1); b) emergent tensions in implementation (Q2); c) necessary support (Q3); and d) the adaptability of QA (Q4). In generating the implications, each of these issues will be examined after collapsing Q2 and Q4 into one discussion focused on the tensions surrounding implementation. Specifically, we will discuss: motivations for implementing an innovation; tensions in implementation of an innovation; and scaling up an educational innovation. Following these discussions, the final section will briefly overview future directions for this line of research by highlighting the limitations of this study and presenting recommendations for further research.

\section{MOTIVATIONS FOR IMPLEMENTING AN INNOVATION}

With respect to the teachers' motivations for implementing QA, fit between QA and what they are already doing is clearly important. What they are doing certainly may differ somewhat as, for example, Laura was interested in science,

Table 4. Summary of Research Question Findings for Each Case

\begin{tabular}{|c|c|c|c|c|}
\hline Question & Answer to Research Question & Laura & Beatty & Wanda \\
\hline $\begin{array}{l}\text { Research } \\
\text { Question 4: }\end{array}$ & $\begin{array}{l}\text { I-BURST rules became a permanent } \\
\text { part of QA }\end{array}$ & $\checkmark$ & & $\checkmark$ \\
\hline \multirow{6}{*}{$\begin{array}{l}\text { In what ways } \\
\text { does Quest } \\
\text { Atlantis } \\
\text { adapt to } \\
\text { local con- } \\
\text { text(s) of } \\
\text { implemen- } \\
\text { tation? }\end{array}$} & $\begin{array}{l}\text { The myth underpinning QA was } \\
\text { deepened }\end{array}$ & & $\checkmark$ & $\checkmark$ \\
\hline & $\begin{array}{l}\text { Ocean World and Healthy World became } \\
\text { a permanent part of QA }\end{array}$ & $\checkmark$ & & \\
\hline & Quests were done internationally & & $\checkmark$ & \\
\hline & $\begin{array}{l}\text { The optional quest response rubric } \\
\text { became a permanent part of } Q A\end{array}$ & & & $\checkmark$ \\
\hline & QA jobs and 3D online community & & & $\checkmark$ \\
\hline & QA board game & & & $\checkmark$ \\
\hline
\end{tabular}


Beatty in social commitments, and all three teachers in writing and higher-level thinking. However, there should also be some value added for the teachers, which here was support for LEP and inclusion students, enthusiasm on the part of the students for the project, and the QA emphasis on empowerment and social commitments.

The "good fit" and the notion of "value added" in implementation and diffusion literature is not new (e.g., Rogers, 1995). However, there is very little design literature that speaks about the notions of empowerment and social commitments. QA work impacting the real world was a major issue for Beatty, which indicates a major finding for designers of technology-rich innovations, a finding that should certainly be investigated further in different contexts with different innovations. Similarly, Both Rogers (1995) and Dormant (1999) emphasized the notions of relative advantage and compatibility. These conceptualizations imply - and this study confirms - that teachers have to see how QA fits with what they're already doing in the classroom, and perceive that it aligns with their pre-existing work.

Also important to implementation was the flexibility and the customizability of QA, which allowed the teachers to, in part, create this "fit" for themselves. A well-documented implementation mantra is that flexibility supports implementation (e.g., Berman \& McLaughlin, 1974, 1978; Fullan \& Pomfret, 1977; Snyder et al., 1996). There have also been attempts to bring this flexibility or modifiability into the design of innovations (Dormant, 1999; Schwartz, Lin, Brophy, \& Bransford, 1999). For the implementation and iterative design of QA, these cases illustrate the finding that customizability was an important part of the teachers' motivations for implementing the innovation.

Another important finding was that the students actually liked QA and enjoyed its implementation. While some educators may bristle at the very idea that an educational innovation should be fun for students, the implementation of QA benefited from the students' enthusiasm and the resultant pressure they put on teachers to implement the innovation. If QA had fallen flat with the students, it surely would have fallen flat with the teachers. Again this speaks to a deep-seated need for broad-based support for an innovation (Berman \& McLaughlin, 1978) and also highlights the notion of fun and centralizes the role of students in the implementation of innovations designed to serve them.

\section{TENSIONS IN THE IMPLEMENTATION OF AN INNOVATION}

The issue of tensions in QA implementation revolved around dealing with chat and e-mail concerns, balancing and providing extrinsic motivators, keeping the implementation of QA on track (maintaining continuity when a teacher was replaced and not letting QA time turn into typing time), and the need for appropriate support (addressed in the next research question). 
The technology-rich aspect of QA brought certain tensions to the forefront that are particularly noteworthy. For many educators and parents, online interactions are somewhat frightening, and as QA is a "cutting-edge" educational tool in many respects, and thus is unfamiliar, it became necessary for these fears to be allayed. Doing so included continual communication between QA staff, teachers, parents, and the school principal, as well as designing QA structures to monitor and archive the online chat and limit spamming within the e-mail system. Additionally, developing and enforcing the I-BURST chat rules contributed to alleviating these tensions. The resolution of such tension represents not only an effective implementation strategy but also the flexible adaptivity of QA (Schwartz et al., 1999).

Flexible adaptivity proved to be a challenge, sometimes resulting in useful adaptations that increased productivity, relative advantage of use, and pedagogical utility and other times resulted in lethal mutations that undermined the pedagogical commitments underlying the project. However, it was important that teachers viewed the program as flexibly adaptive and that they could customize their particular implementation of QA with respect to their local priorities and commitments. In fact, there were numerous times when these three teachers asked about whether they could customize Quests or unit plans and appeared happy with the fact that they could modify these even though they chose to implement them as designed. Each teacher did, however, customize QA to meet her own local needs and the fact that there was not "one way" to implement QA left room for local interpretations and seemed to increase the buy-in of the teachers.

Many serious issues with technology in education have been raised in the literature (e.g., Cuban, 1986, 2001; Healy, 1998; Postman, 1992; Stoll, 1995; 1999). It is important for implementers of technology-rich innovations to be intimately familiar with these concerns so that they can be anticipated and appropriately addressed. With QA, for example, there were some technical issues that had to be dealt with during implementation, including the above-mentioned chat and e-mail concerns. However, the unpredictability of issues underscores the importance of flexibly adaptive design in technology-rich innovations. This also speaks to the importance of technical support for such an innovation's implementation, although the notion of support is multi-faceted and an expanded idea of support as discussed above is appropriate.

\section{SCALING UP AN EDUCATIONAL INNOVATION}

The issue of support was a complex one in this implementation and, as mentioned above, the notion of support must be looked upon as a complex, multidimensional construct. One dimension of this support is enthusiasm for the implementation on the part of the school principal, parents, and other stakeholders. This has been spoken to in the literature (e.g., Berman \& McLaughlin, 1978; Fullan, 1982) and was certainly the case here. 
Because of the technology-rich nature of QA, there must be ample support for dealing with emergent technical issues. Dealing with such problems in a timely manner helped smooth out the implementation of QA. Because QA is a technology-rich innovation, such tech issues may not simply make implementation progress slower, they may threaten to completely foil the entire implementation effort. In addition to this technical aspect of support, assistance with reviewing quests and producing new curricular materials was also important. One teacher, Beatty, implemented QA with an independent stance that required a different sort of support, which is characterized here as "emotional." Dormant's (1999) research and these findings indicate that social relationships between teachers and other stakeholders should be further investigated as part of implementation research agendas, and must be carefully considered by practitioners.

The role of Eydi, the technology support staff member hired by both QA and the school, was clearly very important in the implementation of QA. She helped to deal with technical issues, served as a intermediary between QA designers and teachers, helped develop QA materials, presented quests to classes, reviewed student work, helped train teachers, decorated the computer lab in a way that generated interest in QA, and did many other tasks that supported QA. Earlier research has spoken to the importance of having a full-time supporter of an innovation at the implementation site (Stringfield, Datnow, \& Ross, 1998).

However helpful and important, it is an open question as to whether or not her role in the implementation of QA at Patrick Henry was absolutely essential. The subsequent diffusion of QA to other classrooms in Patrick Henry and to other sites that did not have the benefit of "an Eydi" indicates that such high level support is desirous but may not necessarily be essential if support can be garnered in other ways. It also helped that the full-time supporter of the project was critical of the project but her support involved allowing Beatty to be independent, giving Beatty the emotional support necessary in this context. Support manifested itself in both online and on-site forms, originating from QA staff, the tech coordinator, the principal, the teachers themselves, and even the students. QA activity should extend beyond the computer and the computer lab, and support had to involve computer and non-computer QA work and play. Finally, support must be offered in a way that allows for local ownership and does not lead to dependence upon QA staff and structures.

As discussed above, part of the support for the implementation of QA was in redesign work. QA, during the research period, was a flexibly adaptive structure that changed to meet the needs of teachers, students, and other concerned parties. This flexible adaptivity allowed QA to flourish during and after the research period by allowing teachers of very different abilities and styles (such as Beatty and Laura) to engage, adapt, and successfully implement the technology-rich educational innovation of QA.

Much of the literature on implementation research is related to scaling up educational initiatives; that is, taking them from successful implementation in a 
single context or a few contexts to successful implementation in a large number of contexts (Buechler, 1997; Stringfield et al., 1998). The findings of this study regarding the notion of support speak to the tremendous potential of scaling up QA. To increase in scale, QA or similar innovations must align with the preexisting teacher curricular goals and agendas present in multiple contexts. Thus, the innovation would do well to maintain a flexibly adaptive structure, one that is sensitive and responsive to shifting contextual needs and concerns by empowering its users to make ongoing customizations. Initial support for the innovation should be broad-based, avoiding exclusively top-down or bottom-up approaches to implementation. A full-time on-site supporter of the project would be very helpful, if not essential, and the notion of support must be understood to go beyond the technical element of implementation. This support may at times be technical, but may also take on more emotional or social dimensions. Indeed, the support itself must indeed be flexibly adaptive.

\section{TOWARD A THEORY OF CRITICAL IMPLEMENTATION}

Earlier work on the design of QA sought to develop a critical approach to design by developing relationships with would-be users. This led the design team to develop the concept of critical design ethnography, a participatory, collaborative approach to design that underpinned every element of design (Barab, Thomas, Dodge, Squire, \& Newell, 2004). As a blending of critical ethnography and instructional design work, critical design ethnography allowed us to build local critiques, reify them into a designed artifact, and implement that artifact in classrooms, including the ones examined in this study.

A key finding in this study was the role that the social commitments of QA played in the implementation story. However, this should not simply be understood as an alignment between the design of QA and the social agenda of the teachers (particularly Beatty). The critical approach to design that characterizes critical design ethnography also implies a critical approach to implementation. Further, the social agendas of the students must be considered as well as those of the teachers, designers, principals, staff, and parents. Neglecting the voices of children and their own social agendas simply because of their age subscribes to a view of childhood through a lens of "developmental appropriateness," placing limits on their personal agendas and inscribing power and privilege on adults in the implementation process (Jipson \& Jipson, 2005). Indeed, such developmentalism may be seen as a regime of truth subject to critique and deconstruction (MacNaughton, 2005). We must recognize that just as the teachers in this study have social agendas, so too do students have political views and interests (Habashi, 2005).

Critical design ethnography as a lens for underpinning design must be seen as inextricably connected to a lens for underpinning implementation work. This 
critical implementation of technology-rich innovations in schools must view implementation as an inherently political process that addresses the social commitments of teachers as well as students. It must provide avenues for action and expression for all those touched by the implementation.

\section{REFERENCES}

Barab, S., \& Luehmann, A. (2003). Building sustainable science curriculum: Acknowledging and accommodating local adaptation. Science Education, 87(4), 454-467.

Barab, S. A., \& Squire, K. (2004). Design-based research: Putting a stake in the ground. The Journal of the Learning Sciences, 13(1), 1-14.

Barab, S., Thomas, M., Dodge, T., Squire, K., \& Newell, M. (2004). Critical design ethnography: Designing for change. Anthropology in Education, 35(2) 254-268.

Barab, S. A., Thomas, M. K., \& Merrill, H. (2001). Online learning: From information dissemination to fostering collaboration. Journal of Interactive Learning Environments, 12(1), 105-143.

Berman, P., \& McLaughlin, M. W. (1974). Federal programs supporting educational change, Vol. I: A model of educational change (No. R-1589/1-HEW). Santa Monica, CA: Rand.

Berman, P., \& McLaughlin, M. W. (1975). Federal Programs Supporting Educational Change, Vol. IV: The findings in review (No. R-1589/4-HEW). Santa Monica, CA: Rand.

Berman, P., \& McLaughlin, M. W. (1978). Federal programs supporting educational change, Vol. VIII: Implementing and sustaining innovations (No. R-1589/8-HEW). Santa Monica, CA: Rand.

Brown, A. L. (1992). Design experiments: Theoretical and methodological challenges in creating complex interventions in classroom settings. The Journal of the Learning Sciences, 2(2), 141-178.

Brown, A. L., \& Campione, J. C. (1996). Psychological theory and the design of innovative learning environments: On procedures, principles and systems. In L. Schauble \& R. Glaser (Eds.), Innovations in learning: New environments for education. Hillsdale, NJ: Lawrence Erlbaum Associates.

Buechler, M. (1997). Scaling up: The role of national networks in spreading education reform. Portland, OR: Northwest Regional Educational Laboratory.

Cobb, P., Confrey, J., diSessa, A., Lehrer, R., \& Schauble, L. (2003). Design experiments in education research. Educational Researcher, 32 (1), 9-13.

Cole, M. (1996). Cultural psychology: A once and future discipline. Cambridge, MA: Harvard University Press.

Collins, A. (1992). Toward a design science of education. In E. Scanlon \& T. O'Shea (Eds.), New directions in educational technology. Berlin: Springer-Verlag.

Collins, A., Joseph, D., \& Bielaczyc, K. (2002). Design research: Theoretical and methodological issues. Available online: http://www.extension.harvard.edu/200203/ programs/cte/ext02drt.pdf Retrieved April 2, 2003.

Crandall, D. (1983). The teacher's role in school improvement. Educational Leadership, 41(3), 6-9. 
Crandall, D. P., Loucks-Horsley, S., Baucher, J. E., Schmidt, W. B., Eiseman, J. W., Cox, P. L., et al. (1982). Peoples, policies, and practices: Examining the chain of school improvement (Vol. 1-10). Andover, MA: The NETWORK.

Creswell, J. W. (1994). Research design: Qualitative and quantitative approaches. Thousand Oaks, CA: Sage.

Creswell, J. W. (1998). Qualitative inquiry and research design: Choosing among five traditions. Thousand Oaks, CA: Sage Publications.

Crosthwaite, J., MacLeod, N., \& Malcolm, B. (1997). Case studies: Theory and practice in natural resource management. A paper submitted for the Proceedings of the Australian Association for Social Research Conference, Charles Sturt University, Wagga Wagga.

Cuban, L. (1986). Teachers and machines: The classroom use of technology since 1920. New York: Teachers College Press.

Cuban, L. (2001). Oversold and underused: Computers in the classroom. Cambridge, MA: Harvard University Press.

Dawkins, R. (1976). The selfish gene. New York: Oxford University Press.

Dede, C. (1998). The scaling-up process for technology-based educational innovations. In C. Dede (Ed.), ASCD Year Book 1998: Learning with technology (pp. 199-215). Alexandria, VA: Association for Supervision and Curriculum Development.

Dormant, D. (1999). Implementing human performance technology in organizations. In H. Stolovitch \& E. Keeps (Eds.), Handbook of human performance technology (2nd ed.). San Francisco, CA: Jossey-Bass/Pfeiffer.

Elmore, R. F. (1996). Getting to scale with good educational practice. Harvard Educational Review, 66(1), 1-26.

Erlandson, D. A., Harris, E. L., Skipper, B. L., \& Allen, S. D. (1993). Doing naturalistic inquiry: A guide to methods. Newbury Park, CA: Sage.

Fishman, B., Marx, R. W., Blumenfeld, P., Krajcik, J. \& Soloway, E. (2004). Creating a framework for research on systemic technology innovations. Journal of the Learning Sciences, 13(1), 43-76.

Fishman, B., Soloway, E., Krajcik, J., Marx, R., \& Blumenfeld, P. (2001). Creating scalable and systemic technology innovations for urban education. Paper presented at the Annual Meeting of the American Educational Research Association, Seattle, WA.

Fullan, M. (1982). The meaning of educational change. New York: Teachers College Press.

Fullan, M., \& Pomfret, A. (1977). Research on curriculum and instruction implementation. Curriculum and Instruction, 47, 335-397.

Glaser, B. (1992). Basics of grounded theory analysis. Mill Valley, CA: Sociology Press.

Glaser, B. G., \& Strauss, A. L. (1967). The discovery of grounded theory: Strategies for qualitative research. New York: Aldine Publication Company.

Guba, E. G., \& Lincoln, Y. S. (1983). Competing paradigms in qualitative research. In G. F. Madaus, M. S. Scriven, \& D. L. Stufflebeam (Eds.), Evaluation models: Viewpoints on educational and human services evaluation (pp. 195-220). Boston, MA: Kluwer-Nijhoff Publishing.

Guskey, T. R. (1986). Staff development and the process of teacher change. Educational Researcher, 15(5), 5-12.

Habashi, J. (2005). Freedom speaks. In L. D. Soto \& B. B. Swadener (Eds.), Power and voice in research with children (pp. 21-34). New York: Peter Lang. 
Healy, J. M. (1998). Failure to connect: How computers affect out children's minds and what we can do about it. New York: Touchstone.

House, E. (1979). Technology versus craft: A ten year perspective on innovation. Curriculum Studies 11, 1-15.

Huberman, M. A., \& Miles, M. B. (1984). Innovation up close: How school improvement works. New York: Plenum.

Jipson, J., \& Jipson, J. (2005). Confidence intervals: Doing research with young children. In L. D. Soto \& B. B. Swadener (Eds.), Power and voice in research with children (pp. 35-43). New York: Peter Lang.

MacNaughton, G. (2005). Doing Foucault in early childhood studies. London: Routlege \& Falmer Press.

McLaughlin, M. W. (1990). The Rand change agent study revisited: Macro perspectives and micro realities. Educational Researcher, 19(9), 11-16.

McLellan, H. (1996). Virtual realities. In D. H. Jonassen (Ed.), Handbook of research for educational communications and technology. New York: Macmillan.

Merriam, S. B. (1988). Case study research in education: A qualitative approach. San Francisco, CA: Jossey-Bass.

Miles, M. B., \& Huberman, M. A. (1994). Qualitative data analysis: An expanded sourcebook. London: Sage.

Miles, M. B., \& Louis, K. S. (1990). Mustering the will and skill for change: The findings from a four-year study of high schools that are experiencing real improvement offer insights into successful change. Educational Leadership, 47, 57-61.

Postman, N. (1992). Technopoly: The surrender of culture to technology. New York: Vintage Books.

Randi, J., \& Corno, L. (1997). Teachers as innovators. In B. J. Biddle, T. L. Good, \& I. F. Goodson (Eds.), The international handbook of teachers and teaching (Vol. II, pp. 1163-1221). Dordrecht, The Netherlands: Kluwer.

Rogers, E. (1995). Diffusion of innovations (4th ed.). New York: The Free Press.

Schwartz, D. L., Lin, X., Brophy, S., \& Bransford, J. D. (1999). Towards the development of flexibly adaptive instructional design. In C. M. Reigeluth (Ed.), Instructional-design theories and models: A new paradigm of instructional theory (Vol. 2, pp. 183-213). Mahwah, NJ: Erlbaum.

Slavin, R. E., \& Madden, N. A. (1996). Roots \& Wings Program Design. Retrieved July 1, 2002, from the Success for All Web site: http://www.successforall.net/curriculum/ rwprogdescr.htm

Snyder, J., Bolin, F., \& Zumwalt, K. (1996). Curriculum implementation. In P. W. Jackson (Ed.), Handbook of research on curriculum (pp. 402-435). New York: Macmillan.

Squire, K., MaKinster, J., Barnett, M., Luehmann, A. L., \& Barab, S. A. (2003). Designed curriculum and local culture: Acknowledging the primacy of classroom culture. Science Education, 87(4), 468-489.

Stake, R. E. (1983). Program evaluation, particularly responsive evaluation. In G. F. Madaus, M. S. Scriven, \& D. L. Stufflebeam (Eds.), Evaluation models: Viewpoints on educational and human services evaluation (pp. 287-310). Boston, MA: KluwerNijhoff.

Stake, R. E. (1995). The art of case study research. Thousand Oaks, CA: Sage.

Stoll, C. (1995). Silicon snake oil. New York: Doubleday. 
Stoll, C. (1999). High-tech heretic: Reflections of a computer contrarian. New York: Anchor Books.

Strauss, A. L., \& Corbin, J. (1998). Basics of qualitative research: Techniques and procedures for developing grounded theory (2nd ed.). Thousand Oaks, CA: Sage.

Stringfield, S., Datnow, A., \& Ross, S. M. (1998). Scaling up school restructuring in multicultural contexts: Early observations from Sunland County. Santa Cruz, CA: Center for Research on Education, Diversity \& Excellence.

Yin, R. K. (1981). The case study as a serious research strategy. Knowledge: Creation, Diffusion, Utilization, 3, 97-114.

Yin, R. K. (1989). Case study research: Design and methods (2nd ed.). Newbury Park, CA: Sage.

Direct reprint requests to:

Michael K. Thomas

Department of Curriculum and Instruction

544a Teacher Education Building

225 North Mills Street

Madison, WI 53706-1795

e-mail:mthomas@education.wisc.edu 